\title{
Endocrine Pathology Images Telling the Story of Thousand Words
}

\author{
Zubair W. Baloch • Anne Marie McNicol • \\ Virginia A. LiVolsi
}

Published online: 23 June 2011

(C) Springer Science+Business Media, LLC 2011

In Ivan S. Turgenev's novel, Fathers and Sons, a character Anna Sergeyevna voices "The drawing shows me at one glance what might be spread over ten pages in a book" [1]. As students of pathology, we are very familiar with this concept. A cytologic preparation and/or a hematoxylin and eosin (H\&E) slide represents an untold story that molds into a physical form in our diagnosis, leading to the best available clinical or surgical management of patients.

The endocrine organs and their diseases are not only interesting to us but have been for centuries to numerous artists with interest in human anatomy. The ancient Mayas recognized acromegaly and considered it as an attribute of power [2]. Robertson M.G. et.al described acromegalic features of a sculpture found in sarcophagus tomb in Palenque, Mexico, a region inhabited by ancient Mayas [2]. The first illustrations of the human thyroid gland are in the works of Leonardo da Vinci. An enlarged thyroid gland can be seen in the works of Jan van Eyck (1395-1441), Sandro Botticelli (1445-1510), Albrecht Dürer (14711528), and Michelangelo B (1475-1564) [3].

In order to make use of this visual resource, we extend an open invitation to all contributors and readers of Endocrine Pathology to share their prized, thought-provoking, and most

Z. W. Baloch $(\bowtie) \cdot$ A. M. McNicol $\cdot$ V. A. LiVolsi UPENN Medical Center,

Philadelphia, PA, USA

e-mail: baloch@mail.med.upenn.edu aesthetic cases by publishing them in the new section of this journal Images in Endocrine Pathology.

The author guidelines for publishing in this section can be found in the journal's home page. However, these may be modified in the future in the light of the submissions and feedback from our readers. We envision that the cases published in this section will contain the following:

- Brief history, including relevant clinical, radiological, and biochemical information, e.g., 34-year-old euthyroid woman with a left thyroid mass, an ultrasound-guided FNAwas performed. Should we give an option to include one clinical or radiological image?

- Images: two to six high-quality color pathology images (cytopathology and or histopathology)

- Brief discussion limited to 1-1.5 paragraphs and two to four references.

\section{References}

1. Turgenev I. Fathers and Sons (original title in Russian), The Russian Messenger, 1862.

2. Robertson, MG, Rosenbaum Scandizzo SM, and Scandizzo JR. Physical Deformities in the Ruling Lineage of Palenque, and the Dynastic Implications. The Art, Iconography and Dynastic History of Palenque, Part III, ed, M.G. Robertson,. Robert Louis Stevenson School, Pebble Beach,California. pp. 59-86, 1976

3. Ignjatoviě M. The thyroid gland in works of famous old anatomist and great artists. Langenbecks Arch Surg.395;973-985, 210. 